ERRATA:

Artigo publicado no volume 11 número 1 (DOI 10.1590 / S1516-1846200900100015),

cujo resumo correto segue abaixo:

\title{
SINTOMA VOCAL E SUA PROVÁVEL CAUSA: LEVANTAMENTO DE DADOS EM UMA POPULAÇÃO
}

\section{Vocal symptom and its probable cause: data colleting in a population}

Léslie Piccolotto Ferreira ${ }^{(1)}$, Janine Galvão dos Santos ${ }^{(2)}$, Maria Fabiana Bonfim de Lima ${ }^{(3)}$

\section{RESUMO}

Objetivo: analisar a ocorrência de sintomas vocais e a relação entre a presença deles e sua provável causa na opinião de uma amostra populacional e analisar as correlações possíveis entre sintomas e causas citados. Métodos: participaram da pesquisa 190 frequentadores (18 a 45 anos) de um Shopping Center de São Paulo. Utilizou-se um questionário contendo seis perguntas fechadas do tipo sim/não referentes a aspectos de saúde (incluindo tabagismo), percepção e provável causa de sintomas vocais. A análise dos dados foi realizada pelo teste de Qui-Quadrado. Resultados: os quatro sintomas mais referidos foram: rouquidão $(34,2 \%)$, ardor na garganta $(24,7 \%)$, garganta seca $(21,6 \%)$ e tosse seca (21,6\%); e as causas mais citadas, afecções respiratórias altas $(46,4 \%)$, stress $(14,2 \%)$ e uso intenso da voz $(11,1 \%)$. Foi possível constatar que na opinião dos participantes, a rouquidão está associada ao uso intenso da voz $(p<0,001)$ e às afecções respiratórias altas $(p>0,001)$; a fadiga vocal, ao stress ( $p<0,001)$; o ardor na garganta, às afecções respiratórias altas ( $p<0,001)$; e o pigarro, ao tabagismo $(p=0,021)$ e ao uso de drogas $(p=0,002)$. Conclusão: os dados indicam, portanto, que a população estudada percebe que tanto os fatores externos (stress), como os hábitos (tabagismo e uso de drogas) interferem na produção vocal, assim como os relacionados à saúde e a voz (afecções respiratórias altas e uso intenso da voz).

DESCRITORES: Distúrbios da Voz; População; Epidemiologia; Voz 